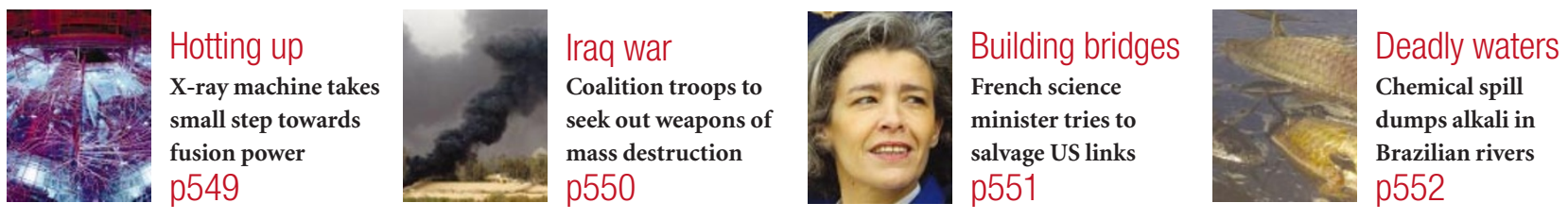

\title{
Researchers get to grips with cause of pneumonia epidemic
}

Jonathan Knight, San Francisco

Four weeks into a major global investigation of the severe acute respiratory syndrome (SARS) outbreak, investigators around the world are still wrestling with key questions about the transmission and origins of the mystery disease.

As of 7 April, 2,601 cases of the disease had been confirmed in 17 countries, causing 98 deaths, according to the World Health Organization (WHO), which is coordinating the investigation. Epidemiologists say that the next few days will reveal the outbreak's likely extent, as health authorities discover whether people who have had no direct contact with known carriers succumb to 'tertiary' infections.

"The next week is critical," says Roy Anderson, an epidemiologist at Imperial College London who specializes in modelling the transmission of infectious diseases. "The key will be whether we start to see cases of tertiary infection."

Possible tertiary infections have already been spotted in Hong Kong. But according to David Heymann, executive director for communicable diseases with the WHO in Geneva, these could still be directly connected to the early, known cases.

In the meantime, the American Association for Cancer Research cancelled its annual conference - one of North America's largest life-sciences meetings - which was due to take place in Toronto this week, in response to concerns about the potential spread of

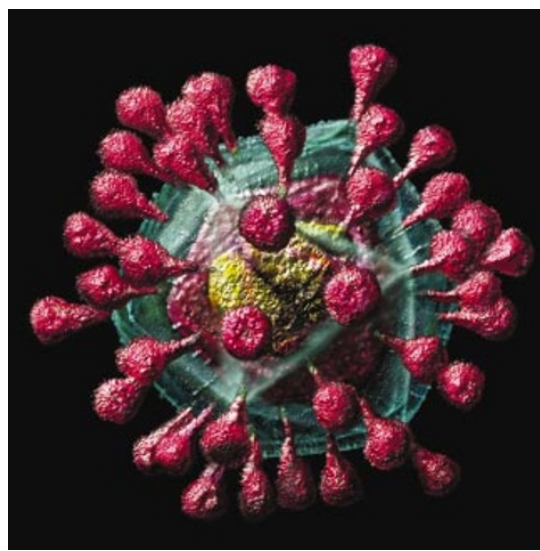

Prime suspect: modified spike proteins on a coronavirus may be at the root of the epidemic.

SARS between hospital staff (see below).

The investigation of SARS is continuing to focus on the role of a new strain of coronavirus - a family of viruses named for the crown of spikes they carry on their surfaces - but researchers are also finding a paramyxovirus in patients, leaving some uncertainty about the cause of the outbreak.

The coronavirus caught the attention of investigators when they saw that samples of it rapidly infected cells in culture dishes, something that other human coronaviruses do not do. Virus rinsed from the lung tissue of patients in Toronto, for example, readily infected monkey kidney cells in tests performed in mid-March. The cells began churning out more virus and six days later began to look abnormal. "The known human coronaviruses do not infect that cell line," says Kathryn Holmes, a virologist at the University of Colorado Health Sciences Center in Denver.

Although known human coronaviruses cause nothing worse than the common cold, some that infect other mammals and birds are much nastier. Avian infectious bronchitis virus, for example, causes a severe respiratory disease and is a major problem in the poultry industry. Close contact between poultry and humans in the Chinese province of Guangdong, where SARS is thought to have originated (see overleaf), has fuelled speculation that the virus that causes it may have jumped species from poultry to humans.

Laboratory tests also suggest that such a species jump has occurred. When the coronavirus was first spotted, for example, the Centers for Disease Control and Prevention (CDC) in Atlanta, Georgia, sent tissue samples and virus cultures from SARS patients to Joe DeRisi, a molecular biologist at the University of California, San Francisco, who had just finished developing a virus-detector chip. This is a glass slide on which are spotted DNA fragments from every virus whose genome has been sequenced - about 1,000 viruses - represented as some 12,000 spots.

On DeRisi's chip, any genetic material from viruses in a sample will bind to the spot containing matching genetic sequences. Fluorescent tags attached to the viral samples

\section{Cancer conference scrapped as outbreak intensifies}

Last Wednesday morning, the American

Association for Cancer Research was all set for the highlight of its year - the gathering of 12,000 researchers for its annual meeting, which was due to start on 5 April in Toronto. "It was all systems go," says Marge Foti, the association's chief executive.

But late that afternoon, the meeting was cancelled - a victim of mounting concern about the potential spread of severe acute respiratory syndrome (SARS), especially among hospital staff. Toronto has been hit harder by the epidemic than anywhere outside Asia - there have been nine deaths there - and organizers decided that holding the meeting there wasn't worth the risk.

The writing was on the wall for the meeting when the Memorial Sloan-Kettering Cancer Center in New York issued a statement advising its staff not to attend. "We told them if they did go they would not be allowed back to work for ten days after the meeting," says Chris Hickey, a spokeswoman for the centre.

Other leading US academic medical centres followed suit and this, together with an increasing flow of cancellations from individual attendees, spelt the end for the meeting. The association will attempt to reschedule it by September, says Foti, but it is unclear how much of the meeting's US\$7-million cost can be salvaged. "It will be devastating financially," Foti says.

Other meetings were proceeding as planned last week - the American College of Physicians, for example, drew 6,500 attendees to its annual meeting in San Diego. "The benefit to practitioners of hearing the latest results on SARS far outweighs the risk," one meeting organizer says. Tom Clarke 
then light up the matching spots, providing a profile of the viruses in the sample.

In the samples sent by the CDC, coronaviruses from several species lit up. The brightest spots were from avian infectious bronchitis virus and a bovine coronavirus. "This suggests that there might have been mixing between viral strains to produce this virus," DeRisi says.

The other current candidate virus in SARS, a type of paramyxovirus known as human metapneumovirus, did not light up. But because the samples were first cultured in monkey cells, it is possible that the metapneumovirus was present in the patients but didn't grow well in cell culture.

Questions about the nature of the new coronavirus will be answered within days, when virologists get hold of the complete genetic sequence now being generated at the CDC. Coronaviruses are unusually prone to incorporating material from their hosts into their genomes, so their sequences carry lots of information about their recent evolutionary past, says Holmes. It will be clear from the sequence whether, for example, bird and cow viruses combined to produce the new strain.

The sequence will also help to determine why the new virus is so much more harmful than other human coronaviruses. One possibility is a difference in the spike proteins that protrude from the cell surface, virologists say. These bind to the cell-surface receptors that pull the viral particle into the cell, so their structure determines what kinds of cell the virus infects.

Although human coronaviruses can survive on a dry surface for up to 3 hours, they are not normally transmitted through the air unless carried in the tiny droplets produced by a sneeze or cough. So close contact with a patient is the normal means of transmission, and this appears to be

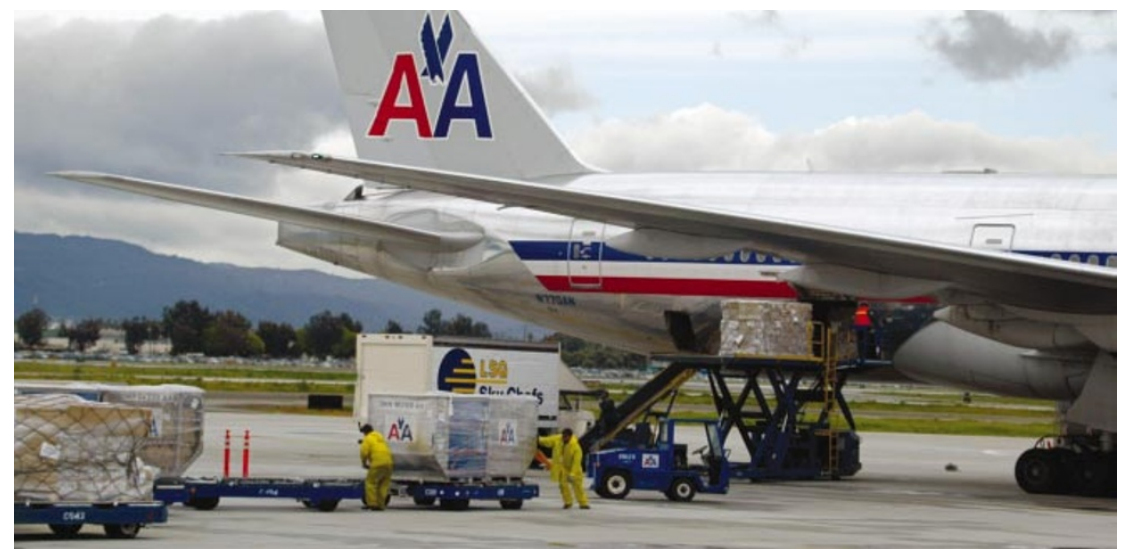

A flight from Tokyo is quarantined at San José airport after three people showed symptoms of SARS.

how the current outbreak is spreading.

Physicians in Toronto and Hong Kong have used broad-spectrum antiviral agents to treat some of the more severe cases of SARS, but are not sure whether the recoveries are the result of the treatment.

And despite the intense focus on the coronavirus, researchers are aware that it may yet prove not to cause the disease, at least on its own. John Tam, director of virology at the Prince of Wales hospital in Hong Kong, has found human metapneumovirus in 25 of 53 SARS patients there, and thinks that it probably plays a role in the illness. Laboratories in Canada and Germany have also found the metapneumovirus in samples.

Metapneumovirus was first discovered in Dutch children with chest infections two years ago (B. G. van den Hoogen et al. Nature Med. 7, 719-724; 2001) and has since been found to exacerbate the health effects of other infections. Tam is now sequencing the virus to see if it is the same as the original Dutch isolate, but his lab has limited resources and he does not know whether this will take weeks or months.

Much of the uncertainty surrounding the contributions of the two viruses could be resolved with the aid of direct tests for their presence in patients, to replace the indirect tests for antibodies to the new coronavirus that have been used so far. CDC officials say that they hope to have such a test for the coronavirus ready to send to US state health departments this week.

If the coronavirus is shown through animal experiments to be the cause of SARS, a direct test could prove critical to stopping its spread, says Michael Lai, who studies coronaviruses at the University of Southern California in Los Angeles.

Patients suspected of having SARS, such as passengers on a flight from Tokyo who were quarantined for two hours at Mineta San José International Airport in California on 1 April, could then be given a more definitive test. "A test will be the most important step at the current time," Lai says.

Additional reporting by David Adam in London and David Cyranoski in Tokyo.

\section{Chinese authorities admit mishandling of Guangdong crisis}

China has apologized for the way in which it handled the outbreak of the mystery pneumonia known as severe acute respiratory syndrome (SARS). The country was lax in informing its citizens and the wider world of the spread of the disease, admitted Li Liming, director of the Chinese Center for Disease Control and Prevention (CDC) in Beijing.

The apology came at a press conference in Beijing on 4 April, as international criticism mounted of China's handling of the outbreak. Liming said he hoped that the apology would reassure visitors to China. But visitors' concerns continue to mount: last week, for example, the United States began to make arrangements to bring home non-essential embassy staff.

As scientists around the world rush to identify the cause of SARS, researchers in China - who could have had a five-month head start - have struggled to get their investigation under way. "We have done a lot of research, but we need help in terms of materials and techniques," says one doctor in Guangdong. "We need expertise, we need primers to help us identify the disease."

The primers - short pieces of genomic sequence used to identify organisms - and other equipment should soon be shipped from laboratories abroad. But until these can be used to test samples from China's patients, it won't even be confirmed that the outbreak in China is the same as that elsewhere, as most experts now assume.

The Chinese CDC says that the coronavirus - regarded by many outside researchers as the most likely cause of the outbreak - is present in only some of the 30 patients tested during its investigation. The bacterium Chlamydia, however, has shown up in every case, they say. As of last weekend, World Health Organization (WHO) investigators had yet to see any samples from a Chinese patient.

The Chinese CDC investigation has been hindered by bureaucratic divisions between the provincial government and Beijing. Even the movement of samples from the province to Beijing research institutes has been slowed down by paperwork, WHO officials say.

Although concern remains, there are reports from doctors in Guangdong that the spread of the disease is slowing. One doctor treating victims of the epidemic in the province ascribes this to successful efforts to isolate patients, improve ventilation in hospitals, and to encourage sanitary measures such as washing hands. But he also says that the disease seems to becomes less infectious as it progresses to secondary and tertiary infections. David Cyranoski 